\title{
Reading Classical Poetry and Humanistic Quality Education for College Students
}

\author{
Yu Wenjing ${ }^{1, a}$, Wu Changlin ${ }^{2, b, ~ * ~}$ \\ ${ }^{1}$ College of Humanities, East China Jiaotong University, Shuang Gang East Street, Nanchang, China \\ ${ }^{2}$ College of Humanities, East China Jiaotong University, Shuang Gang East Street, Nanchang, China \\ a 457028424@qq.com,b309333057@qq.com \\ *Corresponding author
}

Keywords: humanistic quality education; Classical poetry

\begin{abstract}
College students are important talents of the country. It is very important to educate their humanity quality. Humanistic quality education can help college students improve them and contribute to the country under the influence of human culture. The reading of classical poetry is permeated with humanistic quality education. Reading more ancient poetry is conducive to the progress of college students in humanistic knowledge, humanistic ideas, humanistic spirit and humanistic feelings.
\end{abstract}

\section{Introduction}

College students are an important talent resource for social development, an important force and support for social progress and national development. If they want to shoulder this heavy responsibility, they must obtain the comprehensive enhancement in the knowledge, ability, idea, emotion, will and so on. Humanistic quality is a basic quality, which has great influence and penetration on the formation and development of other qualities of College students.

\section{The connotation of "humanistic quality"}

\section{1 "Humanity”}

The term "humanity" first appeared in The Book of Changes, "Masculine and feminine are interlaced, that is nature. Civilization, standardization and education are the humanities." Hou Han Shu also say, "Everything does not depend on astronomical luck, but is devoted to humanities." Astronomical luck and humanity, the former refers to natural phenomena while the latter refers to the unique cultural phenomena of mankind. The interpretation of humanity in Ci Yuan and Ci Hai refers to "all kinds of cultural phenomena in human society".

In the West, the word "humanity" originated from the Latin word "humanitas", which meant human nature, human feelings, civilization, education, etc. In the Renaissance, "humanity” focused on anti theocracy, and attached importance to the value and rights of human beings. Due to the different historical and cultural backgrounds between China and the West, the interpretation of the connotation of "humanity" has different emphasis. The West emphasizes individual independence, highlighting human personality, dignity, freedom and equality; China emphasizes social personality, and pays attention to people's beliefs, ideals, personality and obligations. To sum up the understanding of the word "humanity" in both China and the West, we can define it as various attributes of "human being is human".

\section{2 "Quality”}

There are two classical definitions of "quality". First, it refers to the innate anatomical and physiological characteristics of human beings in the sense of psychology. It mainly refers to the characteristics of sensory organs and nervous system. It is the physiological condition of human 
psychological development. Secondly, in the sense of pedagogy, quality is a relatively stable basic quality or accomplishment which is formed on the basis of innate physiology, through the influence of acquired education and social environment, through the individual's own understanding and social practice. It can be seen that the quality of pedagogy, although also refers to the inherent, more emphasis on education and environment, and it mainly refers to the internalized knowledge and experience. At the same time, quality can be expressed through external forms, such as behaviour (including behaviour norms, habits, people's attitude towards things), thinking quality (including thinking model, mode, depth, angle, agility and creativity), spiritual realm (including the transcendence of self and the height of theory and practice when dealing with all kinds of relationships). [1]

\section{3 "Humanistic quality"}

Humanistic quality is put forward in the all-round development of the society in the new period. It mainly refers to a stable "inner thing" formed by internalizing humanistic knowledge in the body and mind through environment, education and practice in the process of forming people's basic quality. It involves how to deal with the relationship between man and nature, society and others, and the social attributes of man's own reason, emotion and will. [2] Humanistic quality is a reflection of the overall quality of human beings, which is different from the ideological quality, professional quality and physical and mental quality of human beings. It is a concentrated reflection of human knowledge, humanistic spirit, humanistic quality and humanistic feelings. [3,4]

\section{Humanistic quality education}

Humanistic quality education is the inheritance of the outstanding cultural achievements of mankind. It is the internalization of the outstanding cultural achievements of mankind into the personality, temperament and self-cultivation of the educated through the imparting of knowledge, the nurturing of environment and self-practice. It is the inherent quality of human being's relative stability. The ultimate goal of humanistic quality education is to enable students to understand themselves correctly under the influence of human culture, grasp the social pulse, pay attention to human reality and future prospects, so as to promote the internalization of human culture to students' individual psychological quality and thus to improve their overall quality [5].

The content of humanistic quality is embodied in the growth course of human inner spirit and culture, condensed into subjective spiritual world such as human value rationality, moral sentiment and ideal personality, and finally formed national, social and even human spiritual temperament or cultural mode [6]. Its basic connotation is people-oriented, social-oriented, benevolent as the core, to cultivate one's self, govern one's mind, and harmonious people as the goal. It emphasizes education and cultivation, and pays close attention to people's spiritual pursuit and self-perfection. A person's personality, quality and accomplishment will have immeasurable influence on one's life. Perfect personality quality will make people have a positive outlook on life, values and noble spiritual pursuit, so as to make more contributions to society, the country and the people. The inner personality quality of human is formed gradually in the process of the influence, infection and subtle influence of human culture.

The first level of humanistic education is the subject of Humanities (language, literature, history, philosophy, art, etc.) The second level is the education of culture (basic tradition, basic idea, basic spirit, national spirit, national tradition), among which the education of national culture is particularly important. The purpose of cultural education is to accept the basic world outlook, values and behaviour patterns recognized by the nation and to promote mutual recognition between individuals and society. The third level is the education of human consciousness (the basic achievements of human civilization, the common ethics and values of mankind, the common norms of conduct). The purpose of human consciousness education is to enable people to learn to live in harmony with each other. The fourth aspect is spiritual (spiritual realm, spiritual cultivation, ideal personality) education. [7]

Humanistic quality education is conducive to improving the ideological, moral and scientific and 
cultural qualities of College students, cultivating good moral habits of College students, consciously safeguarding social morality, and enhancing the sense of responsibility to the state, society, the collective and others. At the same time, it is also conducive to the formation of correct values and social responsibility for college students. "The highest learning is to cultivate one's moral character, to get close to the masses and to pursue the highest good.” The content of humanistic quality education in "One’s moral character" and "the highest good" is very rich.

\section{Humanistic quality education in classical poetry reading}

In early Qin Dynasty, we advocated “poetry education”, that is, poetry as a teaching material to educate people [8]. In the 5,000-year history of civilization in China, there have been many thinkers, educators and historians such as Laozi, Zhuangzi, Confucius, Mencius, Qu Yuan, Sima Qian, Du Fu, Li Bai and Lu You. Most of them left behind valuable poems, and these poems showed their brilliant thoughts, noble sentiments, tenacious will, loyalty to the country, pursuit of ideals, dedication to career, love of mountains and rivers, the maintenance of justice and hatred of evil. These poems are also immersed in the author's profound experience of society and life, his sincere feelings for others, his sense of mission and responsibility to society, and are good materials for students to carry out humanistic quality education.

\subsection{Master humanities knowledge}

The reserve of humanities knowledge is the soil of cultivating humanistic quality. Humanistic knowledge is a kind of knowledge type corresponding to natural knowledge and social knowledge. It is the grasp, explanation, experience and expression of human world by language and behaviour mode. It mainly refers to the subject knowledge of humanities, including literature, art, language, history, philosophy and other knowledge. Chinese classical literature is the study of human being and the study of human mind. It shows the thoughts, feelings and inner world of all kinds of people in the society. This knowledge can enrich students' knowledge, nourish their spirit, feel the profound emotional world, acquire aesthetic edification, and form a keen perception of life and art and a healthy psychology. It helps students understand the world, understand the society, understand history, understand problems and carry out work.

\subsection{Establish humanistic ideas and humanistic spirit}

Humanistic idea exists and permeates in the basic theory and internal logic of humanistic knowledge. Its core is about value and meaning. Humanistic ideas are conceived in the process of comprehensive reflection on the deep nature of human beings, deepening the understanding of the particularity of human world, and play an important role in people’s thinking and behaviour.

Humanistic spirit refers to people's concern about the meaning and value of human existence in various cognitive and practical activities, and it is a human-centered value pursuit. It is a kind of spiritual motive force in people's heart, which can drive people to pursue a noble realm of life, free and unrestrained emotion and colourful life. This spirit embraces the spirit of science, art and morality, and all the ideas that give humane care. Humanistic spirit is the core and end result of humanistic quality.

"To grasp worldly things is true knowledge, and to understand human mind is the real wisdom." While learning classical poetry, students will naturally be associated with many problems they often encounter in real life, such as human dignity and mission, power and responsibility, ideal and character, harmony and coordination of interpersonal relations, conflicts between individual interests and collective interests, etc. That helps college students broaden their horizons, set lofty goals, and choose the right life pursuits and values.

\subsection{Cultivate humanistic feelings}

Humanistic feelings are a kind of emotional state of people about themselves, society and others. They are the understanding of human nature, the affirmation of human values, the warm care for human beings themselves and the ardent hope for the future of mankind. They reflect people's 
yearning for freedom and the pursuit of spirit. Through the appreciation and comprehension of literary and artistic works, the individual can obtain sensory pleasure and enjoyment, and produce emotional catharsis and resonance, and then deepen the thinking and comprehension of life, life, nature and society, so that the individual mind can be purified in moving, the thought can be cultivated in shock, and the spirit can be sublimated in excitement.

The pastoral poetry contains the survival wisdom of the poet who wants peace and spiritual sublimation from nature. In the poet's view, natural grass, flower, sand and stone can be used in poetry. They respect nature, integrate their feelings with landscape, and advocate the harmony between man and nature. This kind of humanistic idea will be internalized into students' quality in their deep study of classical poetry. Du Fu's poems are deep and desolate, such as "The endless trees fall down on leaves, and the endless Yangtze River rolls in." Wang Wei wrote, "the bright moonlight shines from the pine forest to the ground, and the clear spring water flows past the stone." That reflects the fresh and elegant style of his poetry. Liu Yong's poem "Riverbanks full of willows, gentle winds and incomplete moon" are desolate and cold. Cen Shen's poem "This is like a spring breeze that hung all night, and hundreds of flowers on the pear blossom" are fresh and elegant. Li Bai's world is “only Jing Ting Shan can not make people bored”. Meng Haoran's world is “The field is very open, the sky is lower than the earth, the river is very clear, the moon is very close to people”.

\section{Conclusion}

Excellent classical poems not only let students appreciate the rich and colourful nature, but also make them full of admiration and reverence for nature. Excellent achievements in classical poetry can be internalized into students' personality temperament and cultural accomplishment, giving student's aesthetic edification and accumulation of humanistic connotation. Reading classical poetry is an effective way to improve college students' humanistic quality education.

\section{Acknowledgement}

The work is supported by the education scientific planning project of Jiangxi Province (16YB062).

\section{References}

[1] Liu Xianjun, Knowledge economy calls for the integration of humanities education and science education, Higher education research, 1999,2.

[2] Du Shizhong, Humanistic education theory, Jiangsu education publishing house, 1999,156.

[3] Yu Lidong, Research on Evaluation System of humanities quality education for science and engineering students, Heilongjiang Researches on Higher Education, 2007,5(05): 24.

[4] Xiong Jiansheng, Guo Yu, The content form of Humanistic Quality Education, Theoretical Frontiers, 2016,12:8-11.

[5] Yang Shuzi, Humanistic enlightenment of Chinese Universities, Huazhong University of science and Technology Press.

[6] Wang Bo, Humanistic spirit and Chinese Education, Journal of Shandong Institute of Education, $2001,1$.

[7] Li Xuezheng, Connotation and importance of humanistic quality education for College Students, Journal of Higher Education, 2016, 258-260.

[8] Zu Songlin, Classical literature and quality education, Journal of Shaanxi Normal University philosophy and Social Sciences Edition, 2003, 1. 